\title{
The Integrated City as a Tool for Sustainable Development Abuja Master Plan
}

\author{
Adeponle B.J \\ Advance Space Technology Applications Laboratory, \\ Uyo P.M. B 1223 Uyo, Akwa Ibom State, Nigeria
}

Doi:10.5901/jesr.2013.v3n5p145

\begin{abstract}
Rapid urban expansion without effective environmental consciousness means that in virtually every urban center - from large cities and metropolitan areas to regional centers and small market towns - a substantial proportion of the population is at risk from natural and humaninduced environmental hazards. A strategic approach is essential if urban areas are to enjoy all the benefits which nature can bring. This paper evaluates the concepts of the integrated city and sustainable development. It goes further to assess the general environment of the Federal Capital City, Abuja and the effects of urban growth and development on the cityscape. The environmental consequences of socioeconomic and other activities are evaluated in a bid to determine how sustainable Abuja's urbanization is. The study reveals that the city is growing faster $(13 \%)$ than the provisions of its master plan. It is fast turning into an environmental embarrassment, with developments springing up in gross violation of zoning and other planning codes. Abuja, which was supposed to be an epitome of beauty and an enlightened vision of city development, has suffered over the years from unnecessary distortions in the implementation of its master plan. The paper concludes by suggesting pragmatic strategies such as good urban governance, periodic review of the Abuja master plan, public enlightenment for achieving an integrated and ecologically balanced environment - a Sustainable Abuja City.
\end{abstract}

Keywords: Sustainable development, Integrated city, Building code and Abuja

\section{Introduction}

Growth and development in Nigerian urban areas have been generally unplanned and haphazard. The failure of government to provide basic infrastructure, to plan for imminent growth and expansion, to implement development plans strictly, and to enforce development control has resulted in gross degradation of the environment.

Given the prevalence of poverty, there has been a steady yet unchecked influx of rural migrants to the urban areas, thus leading to an increase in urban population without the institutional and infrastructure framework to bear the resultant effects. Lagos, the erstwhile federal capital, which has expanded beyond its natural boundaries, is a typical example of this phenomenon. Lagos as a federal capital suffered several drawbacks that made its continued existence as Nigeria's capital untenable. Reasons for this include: inadequate land for expansion, urban crises, lack of proper cosmopolitan orientation, lack of locational centrality and urban congestion. This led to the quest for a new national capital.

The concept of Abuja as a befitting Federal Capital Territory, centrally located and without the defects of Lagos was spawned in 1975. This resulted in the convocation of the late Justice Akinola Aguda Panel whose recommendations led to the operationalization of Abuja as Nigeria Federal Capital Territory. The resultant Master Plan was prepared in a way that land use, infrastructure, 
housing, transportation, recreation, economic and social services are coordinated and inter-related. (Abba, 2003). Of the eight objectives of the master plan of the city, five deal essentially with environmental issues. The new capital is expected to conserve the natural and cultural environment of the territory. (FCDA, 1979).

Successive governments in Abuja have neglected these principles. As such, series of distortions to the concept, direction and implementation of the master plan are prevalent today. It is therefore imperative to study the extent of the deviation and proffer pragmatic strategies for a quick containment of the situation and so avert the imminent urban ecological crisis in Abuja. The study examined the relevance of integrating natural and man-made environments into urban development and strategies proffered for achieving a Sustainable Abuja City.

\section{Context of the Research}

The study is set within the Federal Capital City, Abuja, Nigeria. Abuja is on an 8,000 squarekilometer land area bounded by Niger, Kaduna, Plateau and Kwara states. This vast area was considered necessary in order to allow room not just for the capital city but also for a city region that will provide most of the needs of the city, including water, forestry, industrial, agricultural, open spaces, defense, air transport and other needs. The Federal Capital City is expected to cover an area of about 250 square kilometers, while the rest of the Territory of the city region covers about 7,750 square kilometers. (NAPEP, 2003)

The Federal Capital City is located on the Gwagwa Plains in the northeastern quadrant of the Federal Capital Territory. It is bounded by the Abuja Hills to the east and the Zango-Kuku Hills to the south. The site for the Federal Capital City was chosen for it's location at the center of the nation, it's moderate climate, small population and also for political reasons. The horseshoeshaped city has a central axis with the seat of the Nigerian government at its core. On either side of the central area, residential areas are divided into sectors by peripheral highways.

The city was designed as an efficient and attractive environment at each stage of its growth from Phase 1, which was designed to accommodate 230,000 residents through Phases II and III, which were to accommodate 585,000 and 640,000 respectively, to Phase IV aimed at accommodating 1. 7Million. Its ultimate population is estimated at 3.1 million. According to the 1991 population census (Provisional figures), the population of the FCT was 378,671 and Year 2000 projections were put at well over half a million. Phase II of Abuja's development is yet to be completed.

\section{The Integrated City as a Tool for Sustainable Development}

Urban areas in developing countries are faced with similar challenges, including economic viability, deteriorating infrastructure, environmental pollution, social disintegration, loss of community, crime and violence, urban blight, and population growth. In fact, they represent the challenges of maintaining quality of life while facing increasing fiscal constraints, resource limitations, and population growth. Frequently, these challenges are seen as the result of growth and development. Traditional approaches to planning and development are seen, by many, as creating or contributing to these problems, rather than solving them. Community discussions about growth and development tend to portray environmental quality and economic prosperity as mutually exclusive goals. Hence the need for sustainable development. Sustainable development is development that meets the needs of the present without compromising the ability of future generations to meet their own needs (WCED, 1987).

At the heart of the sustainable development movement is the idea that economic growth can and should occur without damaging the social fabric of the community or harming the environment. If sustainable development is to occur, the community-at-large must understand and 
agree that a healthy economy and a healthy environment are both necessary prerequisites for a healthy society. (ICLEI, 1996)

Sustainability is a direction rather than a destination. According to the City of Vancouver (2002), a sustainable city is one that protects and enhances the immediate and long-term well being of the city and its citizens, while providing the highest quality of life possible. Sustainability requires integrated decision-making that takes into account economic, ecological, and social impacts as a whole. A sustainable community is one that seeks improved public health and a better quality of life for all its residents by limiting waste, prevent pollution, maximizing conservation and promoting efficiency, and developing local resources to revitalize the local economy.

Integrated city planning incorporates understanding about how nature works into the ways we design, build, and live. It should be a part of our designs of farms, houses, neighborhoods, cities, transportation systems, technologies, economies, energy policies, and just about anything that directly or indirectly requires energy or materials or governs their use. When human artifacts and systems are well designed, they are in harmony with the ecological patterns in which they are embedded. When poorly designed, they undermine those larger patterns, creating pollution, higher costs, and social stress. (Ravetz, 1998). An Integrated city ensures that cities maintain their civilization. Integrated cities are energy efficient, rely most on renewable energy resources, recycle or reuse at least $60 \%$ of their materials, encourage rather than assault biodiversity, and use composting to help create rather than destroy soil. The possibility and importance of having integrated cities cannot be over-emphasized as showcased in Curitiba Brazil, Midrand-South Africa, Davis- California, Cleveland Ohio and Adelaide Australia amongst others.

\section{The Abuja Master Plan}

The need for a new Federal Capital in Nigeria arose because of the heightened intolerable conditions of living and working in Lagos. The relocation of the Federal Capital to Abuja was necessitated by the need for nexus capital city to be geographically central to Nigeria and with relative equal accessibility to all parts of the nation. About 845 villages were displaced to make way for the FCT. The federal government moved its seat to Abuja between 1982 and 1993.

Reference to the Abuja Master Plan (FCDA, 1979) will reveal that in scope, besides including the major elements of the regional development plan for the Territory, the plan intended to regulate land use, transportation systems, infrastructure, housing and other services in a manner that recognized their inter-relationships and spatial requirements which are paramount in any physical planning exercise of its magnitude.

The master plan of Abuja conceptualized an integrated and sustainable city. The arrangement in the central areas is such that different zones are integrated in a sequential manner, creating a harmonious relationship between them. The land occupied by different zones flow from one into the either, achieved by the use of gridiron street pattern. In the Master Plan, Abuja begins with the smallest unit called the Neighborhood. This unit is designed to serve about 5000 people. This arrangement informed the type of facilities proposed for each Neighborhood, which include a primary school, dispensary, postal agency and a community hall. The next stage is the District, which has more people and upgraded facilities like a secondary school, health and shopping centers, market, post office, police and fire stations. At the top of the pyramid is the City Center, which is also the Central Business District. The City Center houses government offices, government official residences, hospital, transportation terminal and such national symbols like the National Assembly, Supreme Court, National Museum, National Mosque, National Church and the International Conference Center.

Furthermore the Master plan is designed to provide a general framework for the orderly development of the Federal Capital City (FCC) and the satellite towns. The Master plan provides a long-term guidance for the orderly development of the FCC for about 25 years (1976 -2000). According to Ango (2001) strict adherence to the Master Plan would lead to the creation of a 
modern city with a clean and healthy environment whose residents would be free from pollution, traffic jam, congestion, filth, dirt, diseases, delinquency, and all the other things that make life miserable, unhealthy and hazardous for people.

\section{Urbanization in Abuja}

The development of the city was designed to be in four phases with a clearly defined target population of three million inhabitants. Generally, the physical developments in Phase I are completed. The 230,000 populations projected for Phase 1 was distributed among 5 districts: Central Area, Garki (I \&II), Wuse (I \&II), Asokoro and Maitama. Phase II is nearing completion. The detailed design for Phase III has been prepared and the Federal Housing Authority has begun work in the area. Work is yet to commence on Phase IV.

Housing in Abuja is grossly inadequate while the adverse effects of unplanned human settlements in urban and suburban areas in the Federal Capital Territory are already visible. These problems are as a result of the rushed movement of workers from Lagos to Abuja without adequate provision for accommodation. The result was the emergence of a number of shantytowns and squatter settlements occupied by workers and the growing service population in such places as Karu / Nyanya, Karmo and Gwagwalada. These settlements have developed rapidly and are generally unplanned, overcrowded and lacking basic amenities and infrastructure. Although, many of the rushed housing developments within the city area have had to be demolished, the shanty developments persist in the periphery of Abuja especially as there is still little provision for housing accommodation for the low-income workers within the city. Urban dwellers and workers suffer from the poor state of sanitation, congested traffic, air and water pollution and inadequate supply of food and energy needs. The absence of proper implementation in this field calls for a thorough review of urban and regional planning strategies to meet the growing population and the deteriorating situation visible in most parts of the city.

The philosophy of the adopted Federal Capital Territory Plan is to use open space and important urban structuring elements, places for recreation and amenity as follows: A city-wide open space structure based on a longitudinal parkway system interval to the city, retention of the stream valley and water course network for both aesthetic and drainage purposes and preservation of the surrounding escapement of hills and inselbergs which just up in the body of the Gwagwalada plains and form the visual back drop to the city and major focal points within the City". (The Master Plan of Abuja 1979.) In the master plan, provisions were made for the development of a variety of parks and gardens. However, from a survey of the city, it is obvious that only very few parkways, recreational facilities, parks and gardens have been developed. Most of the land allocated to recreation has been put to other uses, mostly residential.

\section{Distortions in the Implementation of the Abuja Master Plan}

Abuja which was supposed to be an epitome of beauty and an enlightened vision of city development, suffered over the years from unnecessary distortions in the implementation of its master plan. The civilian administration that took over from the military regime in 1979 (when the master plan was designed) departed from the principles that underlay the original conception of the new federal capital

The main cause of the distortions of the master plan was the creation of the Ministry of the Federal Capital Territory (MFCT) in 1980 and it's being super imposed on the Federal Capital Development Authority (FCDA). The Ministry lacked the professional personnel to understand the philosophy of a master plan and the need for detailed planning and design to be carried out before the master plan could be transformed into construction activities in any part of the City.

The 1999 International Conference on the Review of the Abuja Master Plan highlighted some distortions (FCDA, 1999). Major distortions include the following: 
1. The ecological survey had underscored the fact that a large part of the territory was still infested with tsetse-fly whilst the river courses still provided breeding grounds for the simulium fly, the carrier of the disease vector giving rise to river blindness. To evacuate the entire human population whose farming activities had helped to keep down and destroy much of the habitat favorable to the tsetse fly was to compromise the future health status of the population of the new capital. The decision to evacuate all the inhabitants had to be revised and compensation and resettlement undertaken only in respect of those occupying the site chosen for building the city and the footprints of that development. This has resulted in the conversion of most of these villages to slums as they accommodate the lower cadre civil servants and other low-income workers.

2. The initial implementation strategy for the Master Plan envisaged that the workers would be housed in the "Accelerated District" within the Phase 1 Area of the city's development. This "Accelerated District" developed for low-income workers so as to prevent the emergence of shanty towns of construction workers in the periphery of the capital city was also to serve as a model for testing out the detailed plan concepts. This was also to prepare the city for a projected population of no more than 160,000 by 1986, the year when the capital was to be formally moved to Abuja. However, seeing the mass of buildings going up in the "Accelerated District", the civilian government took the mistaken decision to rush the movement to Abuja by shifting it forward to the year 1982/83. This decision led to helter-skelter building activities within the city area. It also denied the planners the opportunity to test out the various plan concepts. As such areas such as Nyanya, Lugbe rose up to cater for the population influx.

3. The post-civilian military regime preferred a presidential palace secluded away and closer to Aso Rock than in the middle of the central area of the city where it was located on the Master Plan. The presidential residence was meant to be located on one side of a national square that was to be the intersection of a central mall and a parkway and the National Square. Instead, the present Presidential Villa has usurped the site meant for the National Monument and this makes the beauty and grandeur of such a building no longer part of the prominent and salient feature of Abuja.

4. Initially, building plots in the Federal Capital were allocated on some equitable basis of federal character. However, as geo-political biases became prominent in staffing of the FCDA, distortions became manifest both in the motives for allocation of building plots and in the distribution of allottees.

5. The delay in constructing the transit way and introducing a rapid transit system to serve the City can be regarded as a distortion of the Master plan. This delay has allowed the right of way reserved for the transit way to be encroached upon through indiscriminate plot allocation in several places. This will create a lot of problem in the future for the development of the transit way for buses and eventually a rapid rail system.

6. The Parkway Concept as a major element of open space system is gradually giving way to physical development in Phase 1 and II.

7. Development of Green Areas/Hill Tops for Housing: These and other ancillary facilities are major distortions to the plan. At the same time, these buildings have enhanced the beauty of the city and have added to the housing stock of the city. There are also cases of incidental designs of residential layouts involving some minor redesigns mostly in areas reserved as green to meet the urgent desire for residential development.

In 2003, a Ministerial Committee on Illegal Structures in FCT was constituted to collate a list of all illegal structures in the FCT and present a strategy for demolition. Interestingly, most of the members of the committee were not professional planners.

Some of the distortions highlighted by Committee are presented below. 


\section{TABLE 1: Distortions in the Implementation of Abuja Master Plan Phase I}

\begin{tabular}{|c|c|}
\hline TYPE OF DISTORTION & NUMBER OF PLOTS \\
\hline Encroachment into Green Areas & $\begin{array}{l}84 \text { plots subdivided and allocated as } \\
\text { residential } \\
30 \text { neighborhood parks converted to } \\
\text { corner shops }\end{array}$ \\
\hline Encroachment on Sewer lines & 70plots \\
\hline Encroachment on Water pipelines & 166plots \\
\hline Encroachment into highway corridors & 216 plots \\
\hline $\begin{array}{l}\text { Development of residences on plots allocated for } \\
\text { educational institutions }\end{array}$ & 22 plots \\
\hline
\end{tabular}

Source: Ministry of Federal Capital Territory (2003) Report of Ministerial Committee on Illegal Structures in the FCT

In Phase 1 alone, over five hundred plots contravened the provisions of the Master Plan. Of the 55 plots allocated for educational uses, 22 were converted to residential, thereby causing illegal conversion of residential plots to schools in some areas.

Other distortions identified include changes in land use in respect of public institutions especially in Phase II. Most of these plots have been converted to residential plots. Infringement by public and private developers of housing estates on Primary Infrastructure also occurred. Am example is the Ministers Quarters in Maitama that was not provided for in the Master plan. Squatter settlements have also sprung up to cater for the low-income population and junior civil servants.

The consequences of all these distortions include increased water scarcity as the dams are no longer able to cater optimally for the rapidly growing population; Low voltage electricity and power outages are now being experienced; overhead power lines have become common sight, distorting the panoramic view of the landscape. The master plan proposed underground cabling for both electricity and telecommunication. Furthermore, the conversion of green areas to built-up areas has increased surface run-off of water, hence there is overloading of existing drains thereby increasing the threat of flooding. The construction of buildings without existing infrastructure has led to uncoordinated service provision especially in Phase II. Moreover, the addition of unplanned estates to the master plan has a cumulative effect on the pressure on existing infrastructure.

Based on above-mentioned, it can thus be concluded that :

a. Professionals have not been adequately involved in the drawing up of local environmental policies and the implementation of the Master plan: Administrators rather than professional planners, more often than not get decisive roles in urban planning and development issues, while professional planners only participate on a peripheral basis. The Ministry of Federal Capital Territory as against the Federal Capital Development Authority dictates the pace of physical development

b. Government policies have not been effective in ensuring environmentally sustainable development.: The implementation of the master plan has been defective due to military influence, political Instability, inefficient administration and the corrupt practices of some government officials. Lack of continuity in plans and programs between different administrations and the unstable state of the Nigerian economy and environment has led to distortions.

c. The review of the master plan in 1999, about 21 years after it was designed had been long overdue: Periodical review would have reduced the rate of distortions / deviations from the master plan. The dynamics of any Master Plan is a function of time, technological and political development, financial capability and other factors. A plan 
should be flexible and adaptable. As such, structural plans, rather than master plan should have been used

d. Land use zoning regulations have been poorly enforced. Present development control measures have not been able to curb planning contraventions in the Capital City. There is little or no consideration for treatment of open spaces. Though the master plan made adequate provision for these natural elements, implementation has been faulty leading to loss of planned open spaces. Parks, gardens, and green belts have been either re-zoned or neglected. Integrated planning and sustainability have hence been sacrificed for profit

It is evident from the foregoing that the Federal Capital City hasn't fully met the objectives of sustainable or integrated development which is to: Improve the health and well being of urban dwellers .An appraisal of development in the capital city has also shown that it has not been able to successfully create a balance within the human society as well as balance between humans and nature which is what the concept of the integrated city planning is all about. According to Yanhua (2001), integrated cities should be built on the principles of ecology, which are cycle regeneration to ensure continuity within then urban system, harmonious symbiosis - to ensure integration in the environment, sustainable self-generation and minimum emission

\section{Recommendations}

The sustainable development of the urban environment of Abuja can be achieved by adopting the following strategies:

1. Review of the Operations and Activities of the Federal Capital Development Authority(FCDA) and the Ministry of Federal Capital Territory(MFCT): Overlapping of functions should be avoided by vesting all environmental development responsibilities in the FCDA. FCDA, which is a physical development agency, produced the Master Plan and should be given autonomy as to its implementation. A professional urban planner should head the agency. The departments within the Authority should also be reorganized to suit the stage reached in the development of the city with adequate prominence being given to information dissemination, maintenance and operation. A Parks and Gardens unit should be created in the Physical-Planning Unit and the development control procedures should be re-engineered to achieve better results.

2. Good Urban Governance: Effective development can only be actualized through the application good urban governance to the administration of Abuja. Good Urban Governance implies that city governments respond to and are accountable to all residents, including the poor. It implies inclusive and participatory approaches in which each group and stakeholder has adequate representation. Through good urban governance, citizens are provided with the platform which will allow them to use their talents to the fullest to improve their social and economic conditions. The Global Campaign on Urban Governance was launched in 1999 by the United Nations Human Settlement Programme (UN -Habitat). The campaign seeks to promote growth with equity; hence participatory planning and decision-making are the strategic means for realizing the vision. The campaign proposes that good urban governance is characterized by the following norms: sustainability in all dimensions of urban development; subsidiarity of authority and resources to the closest appropriate level; equity of access to decision making processes and the basic necessities of urban life; efficiency in the delivery of public services and in promoting local economic development; transparency and accountability of decision makers and all stakeholders; civic engagement and citizenship; and the security of individuals and their living environment. These norms which are independent and mutually enforcing are responsive to the issues of the urban poverty and sustainable development (UN-Habitat, 2002) 
3. Periodic Review of the Abuja Master Plan: The Federal Capital Development Authority FCDA should evolve a monitoring programme to set about reviewing the plan periodically. A comprehensive land use survey of all existing developments in the Federal Capital City, showing the realities of today should serve as the basis for plan review and revision where necessary. Furthermore, the landscape objectives of the master plan should be integrated into the overall land use plan. Priority should also be given to the establishment of a data bank for the city facilities. This data bank will contain information about the various infrastructure networks (roads, drainage, water supply, power supply, sewerage and telecommunications) and land use demarcations down to plot layout and sizes.

4. Adoption of Participatory approach to city planning and management. The Environmental Planning and Management (EPM), a continuing and dynamically evolving process which purposes to make urban development policy formulation and implementation progressively more responsive to environmental considerations is ideal. The EPM process is an analytical and descriptive model of urban planning and management that was designed to serve as the technical basis of the Sustainable Cities Programme of the United Nations Human Settlement Programme (UN -Habitat). The goal of EPM is the improvement of health and productivity of cities, through reduction or total elimination of environmental hazards and the protection of natural resources for sustainable socio-economic and physical developments.

The key elements of the EPM process include the identification of urban environmental issues and involvement of stakeholders in issue assessment and priority setting, formulating urban management strategies, formulating and implementing action area plans and institutionalizing the environmental planning and management process. (UNCHS/UNEP, 1987)

5. Public Enlightenment: A pragmatic programme of civic reorientation is necessary. Environmental Education should be included in the school curriculum so that citizens are conscious of environmental principles from an early stage. Also, a revolutionary awareness campaign to sensitize the public on development control procedures and the benefits of ecologically balanced cities should be organized.

\section{Conclusion}

This study establishes the need for sustainable cities. Urban growth and development can be said to be sustainable only when integrated cities that will meet the needs of every urban dweller and at the same time maintain the vitality and viability of the natural environment are the reality. This is imperative for Abuja. The Federal Capital City - despite the distortions - has potentials, which, if properly developed, will result in a city that is both livable and sustainable. But this dream cannot be achieved without a structure that optimizes the economic and societal benefits available without jeopardizing the potential for similar benefits in future.

\section{References:}

Abba. A (2003) Saving the City of Abuja from Dirt, Faeces, Garbage and Disease. Indepth Analysis Vol 3, NO 5 Nov 2003

Ango U.S (2001) implementation of Master Plan: The Abuja Experience 19791999 in FCDA: The Review Of Abuja Master Plan. I badan: Foundation Publication

City of Vancouver (2002) Creating a Sustainable City: Policy Report on Urban Structure and Environmental and Social Development www.city.vancouver.bc.ca

Federal Capital Development Authority (1979) The Master Plan For Abuja - The New Federal Capital Of Nigeria 
Federal Capital Development Authority (1999) Papers Presented at The International Workshop on the Review of Abuja Master Plan

International Council for Local Environmental Initiatives (ICLEI)(1996) The Local Agenda 21 Planning Guide: An Introduction to Sustainable Development Planning.

Ministry of Federal Capital Territory (2003) Report of Ministerial Committee on Illegal Structures in the FCT

National Poverty Eradication Programme (2003) Overview of Abuja: Federal Capital Territory. www.napep.com/states/abuja_states.html

Ravetz. J( 1998) City - Region 2020: Integrated planning for long-term sustainable development Town \& Country Planning Association \& Center for Employment Research, Manchester Metropolitan University

United Nations Commission for Human Settlements/ United Nations Environmental Programme(1987)"Environmental Guidelines for Settlement Planning and Management, Vol 1:Institutionalizing Environmental Planning and Management for Settlements Development". Nairobi: UNCHS

UN-Habitat (2002)The Global Campaign on Urban Governance - Concept Paper", http://www.unhabitat. org/gov 
